\title{
Surface recrystallization - an underestimated phenomenon affecting oxygen exchange activity
}

Tripkovic, Dordije; Kungas, Rainer; Mogensen, Mogens Bjerg; Hendriksen, Peter Vang

Published in:

Journal of Materials Chemistry A

Link to article, DOI:

$10.1039 / \mathrm{c} 9 \mathrm{ta0} 2607 \mathrm{j}$

Publication date:

2019

Document Version

Peer reviewed version

Link back to DTU Orbit

Citation (APA):

Tripkovic, D., Kungas, R., Mogensen, M. B., \& Hendriksen, P. V. (2019). Surface recrystallization - an underestimated phenomenon affecting oxygen exchange activity. Journal of Materials Chemistry $A, 7(19)$, 11782-11791. https://doi.org/10.1039/c9ta02607j

\section{General rights}

Copyright and moral rights for the publications made accessible in the public portal are retained by the authors and/or other copyright owners and it is a condition of accessing publications that users recognise and abide by the legal requirements associated with these rights.

- Users may download and print one copy of any publication from the public portal for the purpose of private study or research.

- You may not further distribute the material or use it for any profit-making activity or commercial gain

- You may freely distribute the URL identifying the publication in the public portal 


\section{Journal of \\ Materials Chemistry A}

\section{Accepted Manuscript}

This article can be cited before page numbers have been issued, to do this please use: . Tripkovi, R. Küngas, M. Mogensen and P. V. Hendriksen, J. Mater. Chem. A, 2019, DOI: 10.1039/C9TA02607J.

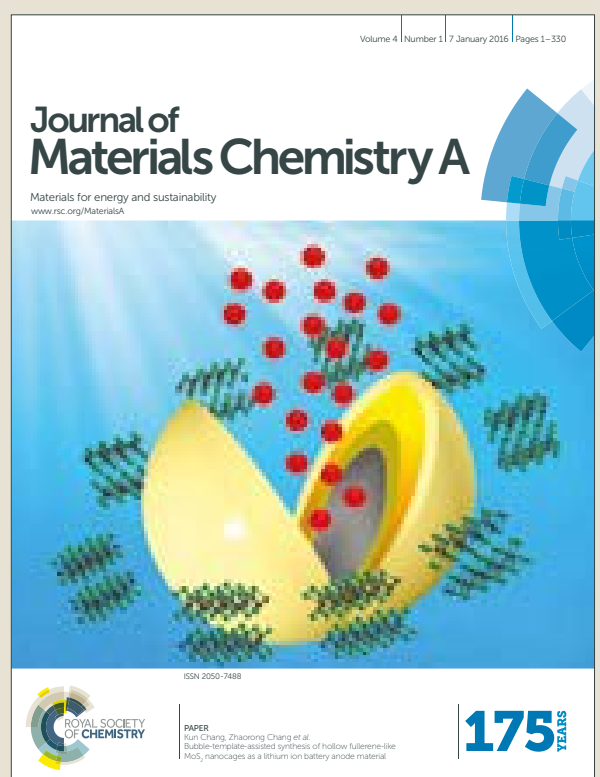

This is an Accepted Manuscript, which has been through the Royal Society of Chemistry peer review process and has been accepted for publication.

Accepted Manuscripts are published online shortly after acceptance, before technical editing, formatting and proof reading. Using this free service, authors can make their results available to the community, in citable form, before we publish the edited article. We will replace this Accepted Manuscript with the edited and formatted Advance Article as soon as it is available.

You can find more information about Accepted Manuscripts in the author guidelines.

Please note that technical editing may introduce minor changes to the text and/or graphics, which may alter content. The journal's standard Terms \& Conditions and the ethical guidelines, outlined in our author and reviewer resource centre, still apply. In no event shall the Royal Society of Chemistry be held responsible for any errors or omissions in this Accepted Manuscript or any consequences arising from the use of any information it contains. 


\title{
Journal of Materials Chemistry A
}

\section{ARTICLE}

\section{Surface recrystallization - an underestimated phenomenon affecting oxygen exchange activity}

Received 00th January 20xx, Accepted 00th January 20xx

DOI: $10.1039 / \times 0 \times x 00000 x$

www.rsc.org/

\author{
Đorđije Tripković, ${ }^{* a}$ Rainer Küngas ${ }^{b}$, and Mogens Bjerg Mogensen ${ }^{a}$, Peter Vang Hendriksen ${ }^{a}$
}

\begin{abstract}
The rate of oxygen surface exchange on $\left(\mathrm{La}_{0.5} \mathrm{Sr}_{0.4}\right)_{0.99} \mathrm{CoO}_{3-\delta}(\mathrm{LSC})$ and $\left(\mathrm{La}_{0.6} \mathrm{Sr}_{0.4}\right)_{0.98} \mathrm{FeO}_{3-\delta}$ (LSF) was investigated by means of Electrical Conductivity Relaxation (ECR) in oxidizing atmospheres $\left(0.2-0.1\right.$ bar $\left.\mathrm{pO}_{2}\right)$ from $650^{\circ} \mathrm{C}$ to $900^{\circ} \mathrm{C}$. We observed reversible and reproducible changes in materials' performance as a consequence of thermal treatment, manifested through drastic changes in surface exchange coefficient $\left(\mathrm{k}_{\mathrm{chem}}\right)$ and the related activation energy with thermal history. The effect is found to be more pronounced in case of LSF, where $k_{\text {chem }}$ at $650^{\circ} \mathrm{C}$ and 0.1 bar $\mathrm{pO}_{2}$ can vary from $3 \cdot 10^{-4}$ to $1.1 \cdot 10^{-5} \mathrm{~cm} / \mathrm{s}$, while bulk properties such as electrical conductivity and the chemical diffusion coefficient of oxygen remain constant. The changes are related to a surface-confined phenomenon and the transition from one state to another is found to follow classical models of nucleation and growth processes. The findings demonstrate the importance of thermal history for studies of oxygen exchange kinetics in perovskite materials and offer an explanation for some of the discrepancies found in the literature.
\end{abstract}

\section{Introduction}

Perovskite oxides belonging to the family; $\left(\operatorname{La}_{1-x} \mathrm{Sr}_{\mathrm{x}}\right)_{s}\left(\mathrm{CO}_{1-}\right.$ $\left.{ }_{y} \mathrm{Fe}_{y}\right) \mathrm{O}_{3-\delta}(0 \leq x \leq 1,0 \leq y \leq 1, s \approx 1)$ have found use as electrodes for solid oxide cells (SOC) and oxygen sensors and are also being explored as potential materials for oxygen separation membranes. This is due to their good ionic and electronic transport properties, high activity for oxygen reduction/evolution reactions (ORR/OER) and the fact that via tailoring the composition the properties can be 'tuned' with a view to the specific application. Preferred compositions that have been widely studied include $\mathrm{La}_{0.6} \mathrm{Sr}_{0.4} \mathrm{CoO}_{3-\delta}, \mathrm{La}_{0.6} \mathrm{Sr}_{0.4} \mathrm{FeO}_{3-}$ $\delta$, and $\mathrm{La}_{0.6} \mathrm{Sr}_{0.4} \mathrm{Fe}_{0.8} \mathrm{Co}_{0.2} \mathrm{O}_{3-\delta}$ designated here as LSC, LSF, and LSCF, respectively. ${ }^{1-5}$ Significant research efforts to improve the catalytic activity of perovskite materials are ongoing, since this could enable faster sensors, and allow SOCs to operate at lower temperatures. This would in turn make SOC technology more cost-competitive through use of cheaper auxiliary materials e.g. the interconnect steel.

Various strategies have been employed to improve the kinetics of the ORR/OER on $(\mathrm{La}, \mathrm{Sr})(\mathrm{Co}, \mathrm{Fe}) \mathrm{O}_{3-\delta}$ electrodes. The most straightforward way of achieving this, and one that has also been extensively pursued, is tuning of the bulk chemical composition of the perovskite by doping. ${ }^{4,6-14}$ In this approach, one has to compromise between obtaining fast reaction kinetics whilst maintaining sufficient thermodynamic stability and suitable mechanical properties. In general, oxygen exchange

\footnotetext{
a. Department of Energy Conversion and Storage, Technical University of Denmark, Risø Campus, Frederiksborgvej 399, 4000 Roskilde, Denmark.

b. Haldor Topsøe A/S, Haldor Topsøes Allé 1, DK-2800, Kgs. Lyngby, Denmark.

*Email - dordijetripkovic@gmail.com, djtri@dtu.dk

Electronic Supplementary Information (ESI) available:

See DOI: $10.1039 / x 0 x x 00000 x$
}

rates increase as more of La in the structure is substituted with $\mathrm{Sr}$ (increasing the vacancy concentration) and as more of the Fe is substituted with Co. For instance, by slightly changing the La:Sr ratio in LSC, Egger et al. ${ }^{4}$ obtained $5 x$ faster reaction kinetics at $725^{\circ} \mathrm{C}$ for $\mathrm{La}_{0.5} \mathrm{Sr}_{0.5} \mathrm{CoO}_{3-\delta}$ in comparison with $\mathrm{La}_{0.6} \mathrm{Sr}_{0.4} \mathrm{CoO}_{3-\delta}$. However, increasing Co content in $(\mathrm{La}, \mathrm{Sr})(\mathrm{Co}, \mathrm{Fe}) \mathrm{O}_{3-\delta}$ leads to a decrease in the thermodynamic stability of the compound and increases the mismatch in coefficient of thermal expansion (CTE) between the perovskite and typical electrolyte materials, e.g. yttria-stabilized zirconia (YSZ) and Gd-doped ceria (CGO). The increase of alkali-earth and Co-content also makes the perovskite more reactive towards zirconia. Unless the physical contact between such perovskites and zirconia is prevented (e.g. by the use of a ceria-based barrier layer), high-resistivity phases, e.g. $\mathrm{La}_{2} \mathrm{Zr}_{2} \mathrm{O}_{7}$ and $\mathrm{SrZrO}_{3}$ are formed at the perovskite-zirconia interface, which leads to a higher area-specific resistance (ASR) of the device. ${ }^{15}$ Finally, due to cation size mismatch and charge interactions, alkaliearth dopants have a tendency to segregate to the surface and form more resistive and/or catalytically less active layers. ${ }^{16-21}$ The material with the composition $\mathrm{La}_{0.6} \mathrm{Sr}_{0.4} \mathrm{Fe}_{0.8} \mathrm{Co}_{0.2} \mathrm{O}_{3-\delta}{ }^{10-12,22}$ offers a good compromise between electrochemical performance and stability/mechanical properties for SOC. Nevertheless, the two 'end-member' materials of the $(\mathrm{La}, \mathrm{Sr})(\mathrm{Fe}, \mathrm{Co}) \mathrm{O}_{3-\delta}$ class; a pure cobaltite (LSC) and a pure ferrite (LSF), are still under study for both sensor and SOC applications, the former due to its superior oxygen exchange properties and the latter due to its virtues with respect to cost, ease of handling, and high stability. ${ }^{2}$ There are also noteworthy attempts to describe the catalytic activities of the materials in terms of other bulk descriptors such as the center of the $\mathrm{O}_{2 p}$ band as proposed by Lee et al. ${ }^{23}$ and the position of Fermi level relative to the conduction band proposed by Jung and Tuller. ${ }^{24}$ 
A fruitful approach to fabrication commercially relevant electrodes with rapid ORR/OER kinetics has been to manufacture composites where perovskites are combined with fast ionic conductors like Gd-doped ceria or even zirconia. ${ }^{5,25-}$ ${ }^{31}$ In such an approach, one utilizes the best properties of the constituting materials - the fluorite serves as the primary path for oxygen ions, while the perovskite provides catalytic activity for oxygen exchange and a path for electrons. Sometimes, besides providing their separate functions for charge transport more elaborate forms of synergy between the two materials have been reported, where a beneficial effect on one material emerges only when the other one is present. For instance, Druce et al. ${ }^{27}$ have shown that oxygen exchange on $\mathrm{Ce}_{0.9} \mathrm{Gd}_{0.1} \mathrm{O}_{2}$ ${ }_{\delta}$ directly benefits from the presence of $\mathrm{La}_{0.6} \mathrm{Sr}_{0.4} \mathrm{Co}_{0.8} \mathrm{Fe}_{0.2} \mathrm{O}_{3-\delta}$, thereby increasing the overall oxygen exchange rate. Similarly, in a recent paper by Ovtar et al., a five-fold improvement in surface reaction kinetics at $750^{\circ} \mathrm{C}$ in comparison to pure $\left(\mathrm{La}_{0.6} \mathrm{Sr}_{0.4}\right)_{0.98} \mathrm{FeO}_{3-\delta}$ has been ascribed to the increased amount of $\mathrm{Ce}_{0.9} \mathrm{Gd}_{0.1} \mathrm{O}_{1.95}$ in the composite. ${ }^{26}$

Finally, a very promising route for enhancing ORR/OER kinetics of this class of perovskite materials is via surface modification. ${ }^{32-38}$ This strategy includes "infiltration": a method where a small amount of an infiltrating agent (typically nitrate precursors with the desired cations) is deposited onto the perovskite surface and after a thermal treatment forms a nanoparticulate surface decoration increasing the catalytic activity. Some groups have reported large improvements of almost 3 orders of magnitude when LSC Ruddlesden-Popper phase (i.e. $\left.(\mathrm{La}, \mathrm{Sr})_{2} \mathrm{CoO}_{4-\delta}\right)$ is placed in contact with the corresponding perovskite $\left((\mathrm{La}, \mathrm{Sr}) \mathrm{CoO}_{3-\delta}\right) \cdot{ }^{39,40}$ Most studies where such large effects have been observed have been done on model electrodes typically in the form of thin dense films. Albeit smaller, beneficial effects have also been reported on more technologically relevant electrodes. ${ }^{41}$

When assessing the efficacy of a particular improvement route, one usually compares the catalytic activity with a reference - a non-modified sample or a literature value. However, establishing a suitable reference point is not necessarily trivial. A good illustration is given by Hayd et al. ${ }^{41}$ where a literature review reveals that area specific resistance of LSC measured by different groups can differ up to 2 orders of magnitude in absolute values, but also deviate strongly with respect to the apparent activation energies. Making meaningful comparisons between results obtained by different groups is further complicated by the fact that thermal history of the samples prior to measurement is rarely detailed in the literature. Furthermore, it is often not clear how stable the reported enhancements are and whether the reference samples have representative and stable performance themselves.

Here, we report the dependence of the oxygen exchange rate on the thermal history of both LSF and LSC. The oxygen exchange was studied via conductivity relaxation on bulk samples. It was found that a high-temperature treatment can lead to a transient enhancement in surface exchange kinetics which diminishes slowly over several days at $650^{\circ} \mathrm{C}$. An important implication of these findings is that differences in thermal history of the samples may account for some of the discrepancies found in the literature for oxygen exchange on LSF and LSC, and potentially other perovskite materials.

\section{Experimental}

All tested samples were in form of dense, rectangular 39 bars prepared from commercial powders (Table 1) by uniaxial pressing at $50 \mathrm{MPa}$ followed by isostatic pressing at $300 \mathrm{MPa}$. Samples were first sintered at $1200^{\circ} \mathrm{C}$ for $4 \mathrm{~h}$, followed by sintering at $1150^{\circ} \mathrm{C}$ for $16 \mathrm{~h}$ with the ramp rate of $120^{\circ} \mathrm{C} / \mathrm{h}$ during heating and $60^{\circ} \mathrm{C} / \mathrm{h}$ during cooldown. Samples were ground gradually on each side with $\mathrm{SiC}$ sandpaper down to grit size of 1000 (removing at least $0.5 \mathrm{~mm}$ of material), followed by fine polishing with diamond paste down to 1 $\mu \mathrm{m}$ diamond particle size. In order to remove glue and leftovers after polishing the samples were rinsed in an ultrasound bath for 5 minutes with acetone, followed by ethanol and finally deionized water. No further thermal treatments were carried after this point and before the first ECR experiment. An illustration of experimental procedure and thermal treatments can be found in the supporting information (S1). Conductivity was measured by the four-probe technique in a quartz tube reactor of approximately $10 \mathrm{ml}$ volume. Contacts were established by twisting high-purity (99.99\%) platinum wires around the samples at the edges (current terminals) and in the center (voltage sensing) with equidistant separation. The testing atmosphere was a dry $\mathrm{N}_{2} / \mathrm{O}_{2}$ mixture with possible impurity being water in amounts less than $100 \mathrm{ppm}$ originating from the oxygen gas. All the experiments were done by changing $\mathrm{pO}_{2}$ from 0.2 to 0.1 bar (reduction runs) and from 0.1 to 0.2 bar (oxidation runs). The total gas flow was kept constant at $5 \mathrm{ml} / \mathrm{s}$ (measured at room temperature) enabling abrupt changes of oxygen partial pressure to be monitored by a zirconia sensor. The temperature was measured with a thermocouple positioned in the vicinity of the sample (within $2 \mathrm{~mm}$ ). The gasses were fed through stainless steel pipes and the rig holding the sample was made of alumina. The relevant experimental values were monitored automatically and logged with the sampling rate of $1 \mathrm{~Hz}$. ECR parameter fitting in this study was done in $E C R e X^{48}$, an in-house built MATLAB ${ }^{49}$ application based on the work of Ciucci ${ }^{50}$ and Otter et al. ${ }^{51}$ ECReX is created in order to address issues frequently experienced by experimentalists conducting ECR and features options such as batch fitting, smoothening, flushing-time correction, plotting etc. More information about the ECR method and parameter fitting can be found in the Electronic Supplementary Information (ESI). The reported values in the results section are average values of two samples for both LSF and LSC, where error bars indicate the maximum and the minimum values. The surface chemistry of the LSF sample after the ECR measurements was analyzed using time-of-flight secondary ion mass spectrometry (TOFSIMS IV from ION-TOF GmbH, Münster, Germany).

\section{Results}

\subsection{Electrical conductivity}

The measured electrical conductivity of the LSC and LSF samples are reproduced in Figure 1. Error bars are less than 5\%. The values are found to be in good agreement with values previously reported in the literature (also included in the plots). ${ }^{2-4,26,52}$ The electrical conductivity of both LSC and LSF decreased with increasing temperature and decreasing $\mathrm{pO}_{2}$ in the experimental range of this work. The electrical conductivity of LSF was roughly 10 times lower than for LSC and showed a maximum value of $250 \mathrm{~S} / \mathrm{cm}$ at $500^{\circ} \mathrm{C}$.

\subsection{Temperature dependence of $\boldsymbol{k}_{\text {chem }}$ and $\boldsymbol{D}_{\text {chem }}$}

As noted in the Experimental section, LSC and LSF samples have not been exposed to high temperatures after grinding and polishing prior 
to the first ECR measurements. We have measured the temperature dependence of the oxygen transport properties by changing the temperature stepwise from 650 to $900^{\circ} \mathrm{C}$ and then from 900 to $650^{\circ} \mathrm{C}$. Remarkably, as seen in Figure 2 , the samples tested in this work showed different behavior in terms of $k_{\text {chem }}$ when measured from low to high (upwards) or from high to low temperatures (downwards). Note that error bars indicating minimum and maximum measured and fitted values are significantly smaller than the observed differences.

Electrical conductivity relaxation results of LSC and LSF have been reported by several groups and are reproduced in the same plot for comparison. $^{1-4}$ While fairly good consensus exists in reported chemical diffusion coefficient $\left(D_{\text {chem }}\right)$ values, there is a large scatter in reported surface oxygen exchange $\left(k_{\text {chem }}\right)$ values for both for LSC and LSF. The apparent activation energies for both heating and cooling runs are listed in Table 2 . Again, the values associated with $k_{\text {chem }}$ vary much more than $D_{\text {chem }}$ counterparts.

\subsection{Long term stability of $\boldsymbol{k}_{\text {chem }}$ and $\boldsymbol{D}_{\text {chem }}$}

Evidently, from the results presented in Figure 2 the measured surface exchange coefficient depends on the thermal history of the sample. The strongest differences are observed at the lower temperatures $\left(650^{\circ} \mathrm{C}\right)$. To investigate the effect further, a new set of conductivity relaxation measurements was carried out over 10 days for both materials. Before the experiment, the samples were treated at $1000^{\circ} \mathrm{C}$ for 10 hours and then the samples were cooled down to $650^{\circ} \mathrm{C}$ in less than an hour. Electrical conductivity stabilizes in less than two hours after the cool-down, but the samples were allowed to equilibrate for a couple of hours more before the first ECR measurement. Hence, the samples are equilibrated with respect to oxygen (the value of $\delta$ in $\left.(\mathrm{La}, \mathrm{Sr})(\mathrm{Fe}, \mathrm{Co}) \mathrm{O}_{3-\delta}\right)$ at the new temperature, before $\mathrm{pO}_{2}$ changes related to the ECR measurements were imposed.

The obtained $k_{\text {chem }}$ and $D_{\text {chem }}$ values are shown as a function of time at $650^{\circ} \mathrm{C}$ in Figure $3 a-b$. The timescale shown on $x$-axis represents the time that has passed since the end of thermal treatment at $1000^{\circ} \mathrm{C}$. The values of $k_{\text {chem }}$ immediately after treatment at $1000^{\circ} \mathrm{C}$ were surprisingly high, reaching $3 \cdot 10^{-4} \mathrm{~cm} / \mathrm{s}$ for LSF and $4.5 \cdot 10^{-4} \mathrm{~cm} / \mathrm{s}$ for $\mathrm{LSC}$ for reduction runs from 0.2 to 0.1 bar $\mathrm{pO}_{2}$. Over the course of ten days, these values gradually decreased over 30x in case of LSF and about 3-4x in case of LSC approaching the values measured initially (S2). At the same time, the diffusion coefficient remained constant and almost equal for both materials at $2 \cdot 10^{-6}$ $\mathrm{cm}^{2} / \mathrm{s}$.

The surface exchange coefficient is inversely proportional to the surface resistance $\left(k_{\text {chem }}{ }^{-1} \sim R_{\text {surf }}\right)$. If the decrease in surface exchange coefficient shown in Figure $3 a$ is instead presented in terms of surface resistance and normalized in a way that $R_{\text {surf }}{ }^{\min }=0$ corresponds to $k_{\text {chem }}{ }^{\max }=3 \cdot 10^{-4} \mathrm{~cm} / \mathrm{s}$ and $R_{\text {surf }}{ }^{\max }=1$ corresponds to $k_{\text {chem }}{ }^{\min }=1 \cdot 10^{-5} \mathrm{~cm} / \mathrm{s}$, we obtain a distinct S-shaped curve as shown in Figure 3c. A similar approach could not be applied for LSC since the $k_{\text {chem }}$ change over 10 days was too small to yield clearly shaped trend when normalized. The obtained S-curve can be well described using the Avrami equation (Eq. 1) which is characteristic of (re)crystallization phenomena. ${ }^{45-47}$

$$
X=1-\exp \left(-\kappa \cdot t^{n}\right)
$$

Here, $X$ represents the extent of the transformation (\%) and $t$ is time

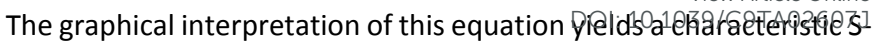
shaped curve. Equation 1 is equivalent to Equation 2:

$$
\ln (-\ln (1-X))=\ln (\kappa)+n \cdot \ln (t)
$$

which is a practical form to determine the Avrami coefficients and $n$ from a double log plot of the extent of transformation versus time. The Avrami coefficients bear information about the rate of transformation and its dimensionality. Parameter $n$ is connected to the dimensionality of growth in the following way:

$$
\boldsymbol{n}=\boldsymbol{a}+\boldsymbol{b} \quad \text { (Eq. 3) }
$$

Parameter $a$ is related to the kinetics of nucleation and takes value of 0 for a fixed number of nucleation sites, and the value of unity when the nucleation rate is constant. Parameter $b$ is related to the dimensionality of growth where $b \approx 1$ corresponds to $1 \mathrm{D}$, needle-like growth; $b \approx 2$ to a $2 \mathrm{D}$, plate-like growth and $b \approx 3$ to a 3D, globular growth. The fitting parameters for LSF are found to be $n \approx 2$ and $k \approx$ $3.8 \cdot 10^{-5} \mathrm{~h}^{-2}$ (Figure 3d).

After the aging period at $650^{\circ} \mathrm{C}$ a third line of experiments was initiated, where the samples were thermally treated stepwise to gradually higher temperatures and the kinetics was measured at $650^{\circ} \mathrm{C}$ and $\mathrm{pO}_{2}=0.2$ (end pressure) bar between each treatment. The results are illustrated in Figure 4 . The first changes to $k_{\text {chem }}$ occurred after a thermal treatment at $800^{\circ} \mathrm{C}$ for 10 hours. Surface exchange coefficient increased from $\approx 4 \cdot 10^{-5} \mathrm{~cm} / \mathrm{s}$ to $\approx 9 \cdot 10^{-5} \mathrm{~cm} / \mathrm{s}$. Further increase in treatment temperature led to an even higher increase in $k_{\text {chem }}$ measured at $650^{\circ} \mathrm{C}$ of up to $\approx 4 \cdot 10^{-4} \mathrm{~cm} / \mathrm{s}$. This indicates that the process influencing the change in surface exchange is triggered in between 700 and $800^{\circ} \mathrm{C}$. It should be noted that $D_{\text {chem }}$ values were again constant throughout the whole experiment $\left(\approx 2 \cdot 10^{-6} \mathrm{~cm}^{2} / \mathrm{s}\right)$.

Surface analysis by ToF-SIMS of the LSF sample after the full sequence of ECR measurement and a cool-down to room temperature in $\mathrm{N}_{2} / \mathrm{O}_{2}$ atmosphere (cooling rate $120^{\circ} \mathrm{C} / \mathrm{h}$ ) is shown in Figure 5. The data provide only a semi-quantitative estimate of the relative differences between bulk and surface contents of a single ionic species and cannot be used to determine the absolute amounts of different elements. While the amount of $\mathrm{La}, \mathrm{Sr}$, and Fe in the bulk (deeper than $\sim 20 \mathrm{~nm}$ from the surface) is constant, the surface is clearly depleted in lanthanum and enriched in strontium and iron. This region extends to a depth of approximately $20 \mathrm{~nm}$. Further screening for possible contaminants such as silicon, chromium, alkali, and alkali-earth ions did not show any significant build-up of these ions (S3-5) even though ICP analysis of the LSF powder showed small amounts of $\mathrm{K}, \mathrm{Na}$, and $\mathrm{Li}(\mathrm{S} 6)$.

\section{Discussion}

The ECR results of LSF and LSC show that surface exchange kinetics can vary substantially over time within the single experimental run and that the measured values can be correlated with thermal history of the sample. As can be seen from Table 2, activation energies of $D_{\text {chem }}$ measured in "upward" and "downward" measurements do not differ significantly when absolute uncertainties related to 
measurement accuracy are taken into account. In contrast, the differences in $k_{\text {chem }}$ values are drastic, especially in case of LSF, where the apparent activation energy upon cooling is halved compared to the activation energy upon heating. Initially surprising, these results become more comprehensible after examining the trends in Figure 3. Since the whole "downward" set of measurements in Figure 2 takes a day, the last measurement in this set at $650^{\circ} \mathrm{C}$ should roughly correspond to the values in Figure $3 a$ after the same amount of time after the high temperature treatment. Indeed, $k_{\text {chem }}$ values of LSF at $650^{\circ} \mathrm{C}$ in Figure 2 is around $2 \cdot 10^{-4} \mathrm{~cm} / \mathrm{s}$, while an identical value can be found in Figure $3 \mathrm{a}, 20 \mathrm{~h}$ after the high-temperature treatment. Similarly, the $k_{\text {chem }}$ value of $1 \cdot 10^{-5} \mathrm{~cm} / \mathrm{s}$ found after the sample has spent 10 days at $650^{\circ} \mathrm{C}$ (Figure 3a) lies close to the first measurement point in Figure 2. Hence, whereas the determined values depend on the thermal history complicating the analysis and comparison to literature, the values are in fact very reproducible. The first measurement point was obtained after polishing and rinsing. After the heating run and some time at $1000{ }^{\circ} \mathrm{C}$, a thermal etching takes places, where the surface develops some roughness and grains protrude from the surface. After the cooling run and long term aging (10 days) at $650^{\circ} \mathrm{C}$, the $\mathrm{k}_{\text {chem }}$ returns to a value close to the original one. This emphasizes that the enhanced exchange rate is not due to the change in morphology at $1000^{\circ} \mathrm{C}$ (creation of surface roughness).

It is also clear that the surface (at temperatures below $700^{\circ} \mathrm{C}$ ) can be in an "activated" state (fast oxygen exchange right after the high temperature treatment) and in a "passivated" state (after several days at $650^{\circ} \mathrm{C}$ ). Further, the sample can reversibly be toggled between these two states; activated by high temperature treatment and passivated by aging at low temperature. This demonstrates difficulties in comparing the results with literature, where thermal history is not always easy to infer. Most likely, some reported $k_{\text {chem }}$ values have been measured on samples in one of the two states. Also, the results presented here illustrate the challenge in using untreated surfaces as reference points in assessing the effects of a certain surface treatment as the baseline materials it-self changes over time. ${ }^{34,53,54}$

Another interesting feature of the observed transition from 'activated' to 'passive' state (in terms of relative change in surface resistance) is that it could be well-described with Avrami equation which is characteristic for phase transformations. The determined Avrami coefficients $\left(n \approx 2\right.$ and $k \approx 3.8 \cdot 10^{-5} \mathrm{~h}^{-2}$ ) imply that the phase transformation is either one-dimensional with constantly emerging nucleation sites or two-dimensional spreading from a fixed number of nuclei. However, the two mechanisms could not be differentiated based on the present data. The fact that the observed effect is confined to temperatures below $700^{\circ} \mathrm{C}$ can explain why in many earlier high-temperature studies it was not observed. However, the trend towards finding better catalysts in so-called 'intermediate temperature region' $\left(500-750^{\circ} \mathrm{C}\right)$ renders this effect important for future studies. In the following text, we discuss some of the possible reasons for the observed trends.

\subsection{ECR fitting procedure}

First of all, it is important to ascertain that the observed variations in $k_{\text {chem }}$ with time are so large that they cannot be merely due to uncertainties arising from the fitting procedure. Some studies have shown that simultaneous fitting of surface oxygen exchange $\left(k_{\text {chem }}\right)$ and bulk diffusion coefficient $\left(D_{\text {chem }}\right)$ complicates accurate assessment of both values from ECR measurments. ${ }^{55}$ Further, $k_{\text {chem }}$ values will be underestimated if the change in oxygenclpartial

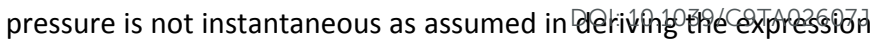
used in the curve-fitting. If the response time approaches the gas switching time $\left(\tau_{\mathrm{ORR}} / \tau_{\text {flush }}<20\right)$, a correction for reactor flushing time must be applied. ${ }^{51}$ This is particularly important in cases where the time constants associated with the oxygen exchange and diffusion are small and approaching the time needed for the surrounding atmosphere to be switched. Our small reactor volume ensures that the complete exchange of atmosphere (flush time) takes place in less than 5 seconds. From the Figure S5 it can be seen that the time constants measured in ECR are in range of thousands of seconds at $650^{\circ} \mathrm{C}$. At higher temperatures, where complete relaxation can take a couple of minutes (depending on sample dimensions) sluggish flushing can lead to lower apparent $k_{\text {chem }}$ values.

Apart from this, depending on the actual $k_{\text {chem }}, D_{\text {chem }}$ and sample geometry, the measured sample can be in surface-, diffusion- or mixed control regime (ESI). The surface-controlled regime, where the estimation of $D_{\text {chem }}$ is unreliable, is usually found at low temperatures, while diffusion control can be seen at higher temperatures. This means that high-temperature $k_{\text {chem }}$ values are encompassed with a larger uncertainty. By selecting particular geometries (Table 1) we ensured that the samples were mostly in the mixed-control regime where both $k_{\text {chem }}$ and $D_{\text {chem }}$ could be determined with satisfactory precision. In fact, the values measured at $650^{\circ} \mathrm{C}$ (where the effect of high-temperature thermal treatment was largest) were the most reliable ones in terms of $k_{\text {chem }}$, thus the clearly observable trend found in Figure $3 a$ is not influenced by the fitting procedure. Yet, the same reasoning can possibly explain the discrepancy in high-temperature $k_{\text {chem }}$ values observed between Søgaard ${ }^{2}$ and the early work of ten Elshof ${ }^{1}$, where the uncertainty on $k_{\text {chem }}$ values above $850^{\circ} \mathrm{C}$ in air is rather large.

\subsection{Variations in composition}

The powders used in this study were fairly pure (Table 1 ). However, small unintended difference in composition could be a reason for discrepancies between values reported here and previous works. Here, it is worth noting that the LSF and LSC results by Søgaard et $a l .2,3$ are obtained in the same lab, but in a different rig more than 10 years ago, using different powders, and yet, values at high temperature are in a very good agreement with the present study. Both LSF and LSC samples used in this study are cation substoichiometric, being $2 \%$ and $1 \%$ A-site deficient, respectively. Therefore, it could be speculated that this small difference in composition is causing the observed trends due to the effect of composition on defect chemistry and/or formation of secondary phases. ${ }^{56}$ We have chosen to work with A-site deficient compositions in order to avoid the formation of hydroxides and carbonates of $\mathrm{Sr}$ and $\mathrm{La}$ upon exposure to water vapour and $\mathrm{CO}_{2}$ present in air, which can lead to mechanical disintegration of the sample. Even though the actual A-site deficiency in the samples can be a little less or more than the desired $1 \%$ and $2 \%$, it is enough to prevent the formation of Sr- and La-rich secondary phases to an extend detectable by X-ray diffraction and to an extend leading to mechanical problems. A/B stoichiometry will influence electrical conductivity; Søgaard et al. ${ }^{57}$ have shown that $2 \%$ A-site substoichiometric LSC can have a significantly higher electrical conductivity and better transport properties $\left(k_{\text {chem }}\right.$ and $\left.D_{\text {chem }}\right)$ in comparison with nominal 
stoichiometric composition. A perfect alignment with the electrical conductivity reported by Egger et al. ${ }^{4}$ on stoichiometric LSC is, therefore, somewhat surprising, but nevertheless indicates that slight substoichiometry in this study did not influence the material significantly. Chemical diffusion coefficient does depend on oxygen vacancy concentration, but changes induced in this way are small and expected to be within the error bar which can be up to $40 \%$ when the measurement is closer to surface controlled regime. By comparison relative changes in $k_{\text {chem }}$ found in this study for LSF are up to $30 \mathrm{x}$ (3000\%), which is around $100 x$ more than the typical uncertainties.

No secondary phases could be observed using CuK $\alpha$ XRD (S7), however, a small amount of Fe- or Co-rich particles can be seen by SEM (S9-11). This phase is likely to be strontium hexaferrite/hexacobaltite $\left(\mathrm{SrFe}_{12} \mathrm{O}_{19}\right.$ or $\left.\mathrm{SrCO}_{12} \mathrm{O}_{19}\right)$ as has been earlier found by a synchrotron study of A-site deficient LSF by Striker et al. ${ }^{56}$ It is known that a small amount of secondary phase can have a strong effect on oxygen reduction reaction. ${ }^{40,41}$ However, the amount and the distribution of this phase was not found to change significantly over time ${ }^{58}$, so this is not likely to be the reason for the observed changes in $k_{\text {chem }}$.

\subsection{Effect of microstructure}

Apparent $D_{\text {chem }}$ values will also be affected by sample porosity. All samples in this study had a relative density of at least $98 \%$ as presented in Table 1. Relative densities of samples from other studies shown in Figure 2 were 99\%, 94\%, 92\% and 93.5\% in cases of S $\varnothing$ gaard $\mathrm{LSC}^{2}$, Egger $\mathrm{LSC}^{4}$, Søgaard $\mathrm{LSF}^{3}$ and ten Elshof ${ }^{1}$, respectively, which likely explains the slight variations in $D_{\text {chem }}$ values in the abovementioned studies.

Sample preparation and sintering in this study was done by following the same procedure as described in Søgaard et al..$^{2,3}$ This has resulted in mean grain size of approximately $430 \mathrm{~nm}$ in case of LSF and $4.3 \mu \mathrm{m}$ in case of LSC (S8-9). Grain size can affect oxygen transport properties as demonstrated by Saher et al. ${ }^{59,60}$ Grain growth is an irreversible process favorable at high temperatures; therefore simple grain growth cannot be the mechanism responsible for the enhancement in surface exchange kinetics we observed after the high-temperature treatment, which we have shown to be reversible in nature (enhancements reported in Figure 4 are for samples exposed to high-temperatures for the second time, following the slow deactivation at $650^{\circ} \mathrm{C}$ ). On the other hand, grain size determines the amount of grain boundaries which can act as a sink or source of impurities or nucleation sites for secondary phases. ${ }^{61}$ Therefore, grain size can affect the rate at which the samples deactivate at $650^{\circ} \mathrm{C}$ following the high-temperature treatment. We estimate that the density of grain boundaries is approximately 40x greater in LSF than in LSC, which could explain why $k_{\text {chem }}$ values are only affected by a factor of 2-3 in case of LSC, while a 30x difference between the activated and passivated states was observed in case of LSF. Further insights by comparison with literature cannot be made since grain size was not specified in the related studies.

\subsection{Surface chemistry}

As outlined above we can exclude that the changes are due to morphological changes on the sample surface, and also that they are due to inaccuracies in fitting stemming from simultaneous fitting with two correlated parameters. The fact that Vie bulk-related $_{\text {a }}$

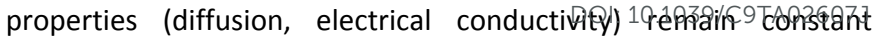
strongly suggests that the observed effect is due to changes occurring on the surface of the samples. The surface of alkaline-earth doped $\mathrm{ABO}_{3}$ perovskites is known to differ from the bulk primarily due to dopant ( $\mathrm{Sr}$ ) segregation at elevated temperatures. Strontium segregation and its effect on oxygen exchange kinetics has been the subject of numerous studies thoroughly summarized in recent review articles. ${ }^{62,63}$ We hypothesize that the observed reversible activation/deactivation phenomenon is the result of compositional modifications of the perovskite surface which are triggered by exposure to elevated temperatures (above $800^{\circ} \mathrm{C}$, see section 4.3).

Several ECR studies have reported a similar decrease in performance over time. Bucher et al. ${ }^{64}$ have observed a decrease in $k_{\text {chem }}$ from $2 \cdot 10^{-4} \mathrm{~cm} / \mathrm{s}$ to $1 \cdot 10^{-4}$ at $600^{\circ} \mathrm{C}$ for $\mathrm{La}_{0.6} \mathrm{Sr}_{0.4} \mathrm{CoO}_{3-\delta}$ in dry $\mathrm{O}_{2^{-}}$ Ar atmosphere after 1000 hours, while $D_{\text {chem }}$ remained constant at $1 \cdot 10^{-6} \mathrm{~cm}^{2} / \mathrm{s}$. The authors associated the observed changes with a 2 $\mathrm{nm}$ thick surface layer enriched in $\mathrm{Sr}$ and $\mathrm{O}$. Further treatment in humid atmospheres led to a more pronounced degradation and $k_{\text {chem }}$ values down to $1 \cdot 10^{-5} \mathrm{~cm} / \mathrm{s}$ accompanied with a similar decrease in $D_{\text {chem }}$ as well. The same authors reported a similar behavior in case of $\mathrm{La}_{0.58} \mathrm{Sr}_{0.4} \mathrm{Fe}_{0.8} \mathrm{Co}_{0.2} \mathrm{O}_{3-\delta}$ in dry $\mathrm{O}_{2}$-Ar at $600^{\circ} \mathrm{C}$, where $k_{\text {chem }}$ dropped from initial $2 \cdot 10^{-6} \mathrm{~cm} / \mathrm{s}$ to $6 \cdot 10^{-7} \mathrm{~cm} / \mathrm{s}$ after 800 hours. ${ }^{65}$ These trends are similar to the transition from "activated" to "passivated" state reported here. Unfortunately, the thermal history of the samples was not detailed and the authors do not report on attempts to reactivate the samples by a high temperature treatment. Furthermore, the authors have found that humidity is contributing to degradation via formation of volatile $\mathrm{Si}(\mathrm{OH})_{4}$. In our study, the samples were exposed only to dry oxygen/nitrogen mixtures with a maximum water content of $100 \mathrm{ppm}$, and a sealed reactor ensures that effects of ambient humidity can be excluded. To the best of our knowledge, no sources of chromium or other possible detrimental materials were in contact with the samples during preparation or testing as also indicated by ToF-SIMS data reproduced in (S2-4).

In a LEIS study by Druce et al. it was found that perovskite-related materials have almost exclusive A-site termination after a thermal treatment at $1000^{\circ} \mathrm{C}$ in oxidizing atmosphere. ${ }^{66}$ Also, it is known that significant strontium segregation can occur even below $600^{\circ} \mathrm{C}^{20}$, which is in good agreement with the ToF-SIMS profiles presented in Figure 5. The near-surface region, which we estimate to be less than $20 \mathrm{~nm}$, can be either a layer of Sr-rich secondary phases, or Sr-rich perovskite/perovskite-related phase such as $\mathrm{LaSrFeO}_{4}$. In the first case, a layer of $\mathrm{Sr}$-rich phase (e.g. $\mathrm{SrO}$ ) would readily react with traces of steam or $\mathrm{CO}_{2}$ forming $\mathrm{Sr}(\mathrm{OH})_{2} \cdot \mathrm{H}_{2} \mathrm{O}$ or $\mathrm{Sr}(\mathrm{CO})_{3}{ }^{17,67}$, respectively (below the decomposition temperature of these phases). In this light, one could conceive a reversible process where SrO converts to hydroxides and/or carbonate at lower temperatures and passivates the surface, while high-temperature treatment removes hydroxides/carbonates and recovers the activity. However, this explanation is inconsistent with phase diagrams for Sr-hydroxides and carbonates (S12) which, for the conditions in this study $\left(\mathrm{H}_{2} \mathrm{O}<\right.$ $\left.100 \mathrm{ppm}, \mathrm{CO}_{2}<<100 \mathrm{ppm}\right)$, are expected to decompose below 300 and $600^{\circ} \mathrm{C}$, respectively.

Finally, an alternative and, in our opinion, the most plausible explanation is that a layer of SrO or related detrimental secondary 
phases is already covering the samples at relatively low temperatures, and gets transformed into perovskite or perovskiterelated phase with an increased amount of Sr (e.g. RuddlesdenPopper phase) at elevated temperatures. Such surface termination would correspond to the activated state with a very low activation energy and high ORR/OER activity (low surface resistance). Upon cooling, the surface then gradually transforms into passivated layer containing less active phases with high activation energy (high surface resistance). An illustration of the process is given in Figure 6 . The transformation from one state to the other follows the Avrami type behavior and is likely taking place in the outermost layer of approximately $20 \mathrm{~nm}$ as observed by SIMS profiling. The formation of Ruddlesden-Popper phases at the perovskite surface has been reported in literature in case of $\mathrm{La}_{0.65} \mathrm{Sr}_{0.35} \mathrm{MnO}_{3-\delta}$ by Dulli et al. ${ }^{68}$ and in $\mathrm{SrTiO}_{3}$ by Szot and Speier ${ }^{69}$ after thermal treatment $800^{\circ} \mathrm{C}$ in both oxidizing and reducing atmospheres. On the other hand, Feng et al. have found Ruddlesden-Popper phase already at $350^{\circ} \mathrm{C}$ in air at the surface of epitaxial $\mathrm{La}_{0.8} \mathrm{Sr}_{0.2} \mathrm{CoO}_{3-\delta}$ thin films. ${ }^{70}$ The same group, using the same material has also shown that the changes in surface chemistry are reversible and can be altered by electrochemical reduction/oxidation. ${ }^{71}$ Similar and reversible activation/deactivation cycles under cathodic/anodic polarization have been reported for the case of ( $\mathrm{La}, \mathrm{Sr}) \mathrm{MnO}_{3-\delta}$ and has been interpreted by dissolution of a passive $\mathrm{SrO}$ layer into the underlying perovskite lattice. ${ }^{72-74}$ Thus, hypothesizing that a reversible reconstruction of the surface is taking place on thermal cycling seems reasonable assuming that the perovskite materials used in this study are analogous to the materials discussed above. A way to test this hypothesis would be to thoroughly analyze the surface of the material at different points in time during the deactivation process. This, however, is beyond the scope of this work and will be the subject of an upcoming study. ${ }^{58}$

\section{Conclusions}

The electrical conductivity of LSC and LSF was found to decrease with the increasing temperature and decreasing $\mathrm{pO}_{2}$, which is consistent with the literature and as expected for p-type conductors. Electrical conductivity at $650^{\circ} \mathrm{C}$ and at $\mathrm{pO}_{2}$ of 0.1 was found to be $2050 \mathrm{~S} / \mathrm{cm}$ and $250 \mathrm{~S} / \mathrm{cm}$ for LSC and LSF, respectively. Electrical conductivity relaxation measurements revealed large differences in the temperature-dependence of the oxygen exchange kinetics between heating and cooling runs, which were found to be a consequence of thermal treatment at high temperatures. Treating samples in $\mathrm{O}_{2} / \mathrm{N}_{2}$ mixture at $1000^{\circ} \mathrm{C}$ for 10 hours led to a transient enhancement in surface exchange coefficient with values almost 2 orders of magnitude higher than reported in literature. On prolonged thermal treatment at $650^{\circ} \mathrm{C}$ (over weeks) this enhancement was gradually lost again especially in case of LSF where $k_{\text {chem }}$ dropped almost $30 x$ (from $3 \cdot 10^{-4}$ to $1.1 \cdot 10^{-5} \mathrm{~cm} / \mathrm{s}$ ) after 10 days. The transient reduction in performance was found to be well described by an Avrami-equation. The beneficial effect of thermal treatment at high temperatures was found to be reversible and effective at $800^{\circ} \mathrm{C}$ and above. The phenomenon is most likely related to a reversible surface transformation via two-dimensional crystallization mechanism. The surface of LSC and LSF can be toggled between an "activated" and "passivated" state with significantly differentew ARR/OERR activation energies. The results illustrate the impolptance 0 of thermal history for the oxygen surface exchange kinetics, differences in which may explain some of the discrepancies in $\mathrm{k}_{\text {chem }}$ values reported in literature for one and the same material.

\section{Conflicts of interest}

There are no conflicts to declare.

\section{Acknowledgements}

Financial support by Danish innovation fund (Innovationsfonden) within the SYNFUEL project 4106-00006B is gratefully acknowledged. Authors would like to thank Kion Norrman for performing ToF-SIMS analysis.

\section{References}

1

J. E. ten Elshof, M. H. R. Lankhorst and H. J. M. Bouwmeester, J. Electrochem. Soc., 1997, 144, 1060.

2 M. Søgaard, P. V. Hendriksen, M. Mogensen, F. Poulsen and E. Skou, Solid State lonics, 2006, 177, 3285-3296.

3 M. Søgaard, P. V. Hendriksen and M. Mogensen, J. Solid State Chem., 2007, 180, 1489-1503.

A. Egger, E. Bucher, M. Yang and W. Sitte, Solid State Ionics, 2012, 225, 55-60.

5 P. Hjalmarsson, M. Søgaard and M. Mogensen, Solid State Ionics, 2008, 179, 1422-1426.

S. Carter, A. Selcuk, R. J. Chater, J. Kajda, J. A. Kilner and B. C. H. Steele, Solid State Ionics, 1992, 53-56, 597-605.

P. Hjalmarsson, PhD Thesis, 2008.

8 P. Hjalmarsson, M. Søgaard, A. Hagen and M. Mogensen, Solid State lonics, 2008, 179, 636-646.

9 P. Hjalmarsson, M. Søgaard and M. Mogensen, Solid State Ionics, 2009, 180, 1395-1405.

10 B. T. Dalslet, M. Søgaard, H. J. M. Bouwmeester and P. V. Hendriksen, Solid State Ionics, 2009, 180, 1173-1182.

11 B. T. Dalslet, M. Søgaard and P. V. Hendriksen, Solid State lonics, 2009, 180, 1050-1060.

12 J. W. Stevenson, T. R. Armstrong, R. D. Carneim, L. R. Pederson and W. J. Weber, J. Electrochem. Soc., 1996, 143, 2722-2729.

13 J. E. ten Elshof, H. J. M. Bouwmeester and H. Verweij, Solid State lonics, 1995, 81, 97-107.

14 Y. Ren, R. Küngas, R. J. Gorte and C. Deng, Solid State lonics, 2012, 212, 47-54.

15 A. Mitterdorfer and L. J. Gauckler, Solid State Ionics, 1998 111, 185-218.

16 W. Lee, J. W. Han, Y. Chen, Z. Cai and B. Yildiz, J. Am. Chem. Soc., 2013, 135, 7909-7925.

D. Oh, D. Gostovic and E. D. Wachsman, J. Mater. Res. 2012, 27, 1992-1999.

18 J. Druce, T. Ishihara and J. Kilner, Solid State Ionics, 2014, 
262, 893-896.

19

W. Jung and H. L. Tuller, Energy Environ. Sci., 2012, 5, 5370-5378.

20 M. Kubicek, G. M. Rupp, S. Huber, A. Penn, A. K. Opitz, J. Bernardi, M. Stöger-Pollach, H. Hutter and J. Fleig, Phys. Chem. Chem. Phys., 2014, 16, 2715.

21 Z. Cai, M. Kubicek, J. Fleig and B. Yildiz, Chem. Mater., 2012, 24, 1116-1127.

22 S. Wang, P. a W. van der Heide, C. Chavez, a J. Jacobson and S. B. Adler, Solid State Ionics, 2003, 156, 201-208. Y.-L. Lee, J. Kleis, J. Rossmeisl, Y. Shao-Horn and D. Morgan, Energy Environ. Sci., 2011, 4, 3966. W. Jung and H. L. Tuller, Adv. Energy Mater., 2011, 1, 1184-1191. S. Cheng, H. Huang, S. Ovtar, S. B. Simonsen, M. Chen, W. Zhang, M. Søgaard, A. Kaiser, P. V. Hendriksen and C. Chen, ACS Appl. Mater. Interfaces, 2016, 8, 4548-4560. S. Ovtar, M. Søgaard, K. Norrman and P. V. Hendriksen, J. Electrochem. Soc., 2018, 165, F220-F231.

J. Druce, H. Téllez, T. Ishihara and J. a. Kilner, Faraday Discuss., 2015, 182, 271-288.

W. Ma, J. J. Kim, N. Tsvetkov, T. Daio, Y. Kuru, Z. Cai, Y. Chen, K. Sasaki, H. L. Tuller and B. Yildiz, J. Mater. Chem. A, 2015, 3, 207-219.

Y. Chen, Z. Cai, Y. Kuru, W. Ma, H. L. Tuller and B. Yildiz, Adv. Energy Mater., 2013, 3, 1221-1229.

P. Hjalmarsson and M. Mogensen, J. Power Sources, 2011, 196, 7237-7244.

P. Hjalmarsson, J. Hallinder and M. Mogensen, J. Solid State Electrochem., 2012, 16, 2759-2766.

D. Ding, X. Li, S. Y. Lai, K. Gerdes and M. Liu, Energy Environ. Sci., 2014, 7, 552.

T. Hong, F. Chen and C. Xia, Electrochem. commun., 2015, 51, 93-97.

Hong, M. Zhao, K. Brinkman, F. Chen and C. Xia, ACS Appl. Mater. Interfaces, 2017, acsami.6b14625. D. Lee, Y.-L. Lee, W. T. Hong, M. D. Biegalski, D. Morgan and Y. Shao-Horn, J. Mater. Chem. A, 2015, 3, 2144-2157. M. Sase, K. Yashiro, K. Sato, J. Mizusaki, T. Kawada, N. Sakai, K. Yamaji, T. Horita and H. Yokokawa, Solid State lonics, 2008, 178, 1843-1852.

E. J. Crumlin, E. Mutoro, S.-J. Ahn, G. J. la O', D. N. Leonard, A. Borisevich, M. D. Biegalski, H. M. Christen and Y. ShaoHorn, J. Phys. Chem. Lett., 2010, 1, 3149-3155. E. J. Crumlin, E. Mutoro, S.-J. J. Ahn, G. J. La O, D. N. Leonard, A. Borisevich, M. D. Biegalski, H. M. Christen, Y. Shao-Horn, G. J. la O', D. N. Leonard, A. Borisevich, M. D. Biegalski, H. M. Christen and Y. Shao-Horn, J. Phys. Chem. Lett., 2010, 1, 3149-3155.

40 M. Sase, F. Hermes, K. Yashiro, K. Sato, J. Mizusaki, T. Kawada, N. Sakai and H. Yokokawa, J. Electrochem. Soc., 2008, 155, B793.

41 J. Hayd, H. Yokokawa and E. Ivers-Tiffee, J. Electrochem. Soc., 2013, 160, F351-F359.

42 P. J. Gellings and H. J. Bouwmeester, Handbook of Solid State Electrochemistry, 1997. J. M. Vohs and R. J. Gorte, Adv. Mater., 2009, 21, 943-956.

J. Maier, Solid State lonics, 1998, 112, 197-228 ew Article Online B. T. Dalslet, University of Twente, 2008.10.1039/C9TA02607J M. Avrami, J. Chem. Phys., 1939, 7, 1103-1112. M. Avrami, J. Chem. Phys., 1940, 8, 212-224. M. Avrami, J. Chem. Phys., 1941, 9, 177-184. Đ. Tripković, https://sites.google.com/view/ecrex. MATLAB 2016a, The MathWorks Inc., Natick, Massachusetts.
F. Ciucci, Solid State Ionics, 2013, 239, 28-40.

M. W. den Otter, H. J. M. Bouwmeester, B. A. Boukamp and H. Verweij, J. Electrochem. Soc., 2001, 148, J1.

M. Mosleh, N. Pryds and P. V. Hendriksen, Mater. Sci. Eng. B, 2007, 144, 38-42.

T. Hong, F. Chen and C. Xia, J. Power Sources, 2015, 278, 741-750.

M. Li, Z. Sun, W. Yang, T. Hong, Z. Zhu, Y. Zhang, X. Wu and C. Xia, Phys. Chem. Chem. Phys., 2017, 19, 503-509. R. A. Cox-Galhotra and S. McIntosh, Solid State lonics, 2010, 181, 1429-1436.

T. Striker, J. A. Ruud, Y. Gao, W. J. Heward and C. Steinbruchel, 2007, 178, 1326-1336.

M. Søgaard, P. V Hendriksen, F. W. Poulsen and M. Mogensen, J. Electroceramics, 2004, 13, 811-816. Đ. Tripković, J. Wang, R. Kungas, B. Yildiz, P. Vang Hendriksen and M. B. Mogensen, In preparation. S. Saher, M. Meffert, H. Störmer, D. Gerthsen and H. J. M. Bouwmeester, J. Mater. Chem. A, 2017, 5, 4982-4990. M. A. Haider and S. McIntosh, J. Electrochem. Soc., 2011, 158, B1128.

M. Niania, R. Podor, T. Ben Britton, C. Li, S. J. Cooper, N. Svetkov, S. Skinner and J. Kilner, J. Mater. Chem. A, 2018, 6, 14120-14135.

Y. Li, W. Zhang, Y. Zheng, J. Chen, B. Yu, Y. Chen and M. Liu, Chem Soc. Rev., 2017, 46, 6345-6378.

B. Koo, K. Kim, J. K. Kim, H. Kwon, J. W. Han and W. C. Jung, Joule, 2018, 2, 1476-1499.

E. Bucher, W. Sitte, F. Klauser and E. Bertel, Solid State lonics, 2012, 208, 43-51.

E. Bucher and W. Sitte, Solid State Ionics, 2011, 192, 480482.

J. Druce, H. Téllez, M. Burriel, M. D. Sharp, L. J. Fawcett, S. N. Cook, D. S. McPhail, T. Ishihara, H. H. Brongersma and J. A. Kilner, Energy Environ. Sci., 2014, 7, 3593-3599. Y. Yu, H. Luo, D. Cetin, X. Lin, K. Ludwig, U. Pal, S. Gopalan and S. Basu, Appl. Surf. Sci., 2014, 323, 71-77.

H. Dulli, P. A. Dowben, S. H. Liou and E. W. Plummer, Phys. Rev. B - Condens. Matter Mater. Phys., 2000, 62, R14629R14632.

K. Szot and W. Speier, Phys. Rev. B, 1999, 60, 5909. Z. Feng, Y. Yacoby, M. J. Gadre, Y. L. Lee, W. T. Hong, H. Zhou, M. D. Biegalski, H. M. Christen, S. B. Adler, D. Morgan and Y. Shao-Horn, J. Phys. Chem. Lett., 2014, 5, 1027-1034.

E. Mutoro, E. J. Crumlin, H. Pöpke, B. Luerssen, M. Amati, M. K. Abyaneh, M. D. Biegalski, H. M. Christen, L. Gregoratti, J. Janek and Y. Shao-Horn, J. Phys. Chem. Lett., 2012, 3, 40-44. 
72

A.-K. Huber, M. Falk, M. Rohnke, B. Luerssen, M. Amati, L. Gregoratti, D. Hesse and J. Janek, J. Catal., 2012, 294, 7988.

73 W. Wang and S. P. Jiang, Solid State lonics, 2006, 177, 1361-1369.

74 G. J. la O', R. F. Savinell and Y. Shao-Horn, J. Electrochem. Soc., 2009, 156, B771-B781. 


\section{Journal of Materials Chemistry A}

\section{ARTICLE}

\section{Tables and Figures}

Table 1. Samples used in this study

\begin{tabular}{|c|c|c|c|c|c|}
\hline & Composition & Powder Supplier & Purity & Density & Dimensions (mm) \\
\hline \multirow{2}{*}{ LSC } & \multirow{2}{*}{$\left(\mathrm{La}_{0.6} \mathrm{Sr}_{0.4}\right)_{0.99} \mathrm{CoO}_{3-\delta}$} & \multirow{2}{*}{ CerPoTech AS } & \multirow{2}{*}{$>99 \%$} & \multirow{2}{*}{$>99 \%$} & $2.16 \times 2.13 \times 17.70$ \\
\hline & & & & & $2.04 \times 2.01 \times 18.50$ \\
\hline \multirow{2}{*}{ LSF } & \multirow{2}{*}{$\left(\mathrm{La}_{0.6} \mathrm{Sr}_{0.4}\right)_{0.98} \mathrm{FeO}_{3-\delta}$} & \multirow{2}{*}{ Kusaka Rare Metal Products Co.Ltd. } & \multirow{2}{*}{$>99 \%$} & \multirow{2}{*}{$>98 \%$} & $3.70 \times 0.75 \times 17.60$ \\
\hline & & & & & $3.40 \times 3.45 \times 18.60$ \\
\hline
\end{tabular}

Table 2. Activation energies of $k_{\text {chem }}$ and $D_{\text {chem }}$ for LSC and LSF. "Upwards" and "downwards" refer to measurements from low to high temperatures and viceversa, respectively. (note: literature values are estimated by linear fit through the reproduced data points)

\begin{tabular}{|c|c|c|}
\hline Results and references & $\mathrm{E}_{\mathrm{A}}\left(\mathrm{k}_{\mathrm{chem}}\right)[\mathrm{kj} / \mathrm{mol}]$ & $\mathrm{E}_{\mathrm{A}}\left(\mathrm{D}_{\text {chem }}\right)[\mathrm{kj} / \mathrm{mol}]$ \\
\hline LSC upwards & $183 \pm 18$ & $86 \pm 6$ \\
\hline LSC downwards & $124 \pm 7$ & $102 \pm 5$ \\
\hline LSC (M.Søgaard et al.) $)^{2}$ & - & $79 \pm 5$ \\
\hline LSC (A.Egger et al.) $)^{4}$ & 165 & 129 \\
\hline LSF upwards & $185 \pm 7$ & $114 \pm 6$ \\
\hline LSF downwards & $92 \pm 6$ & $110 \pm 3$ \\
\hline LSF (M.Søgaard et al.) $)^{3}$ & $199 \pm 23$ & 137 \\
\hline LSF (J.E. ten Elshof et al. $)^{1}$ & $131 \pm 14$ & $81 \pm 12$ \\
\hline
\end{tabular}



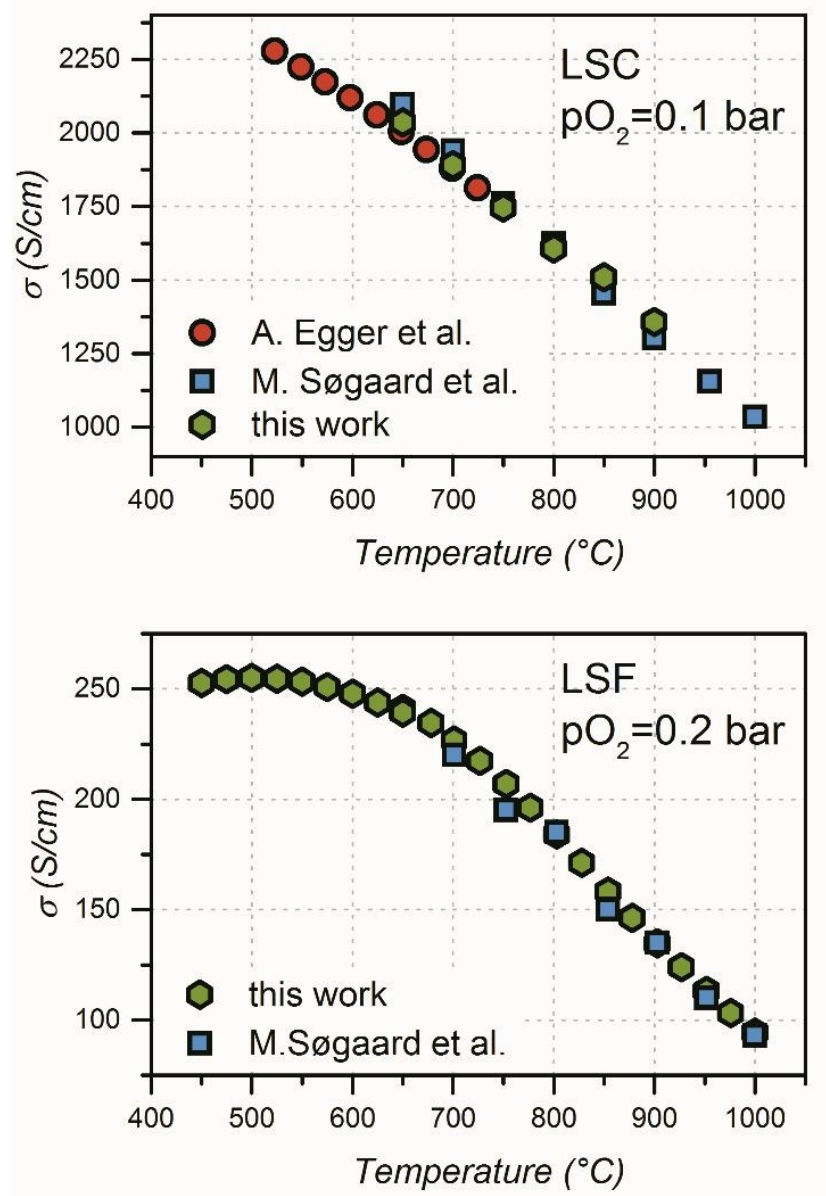

Fig. 1. Electrical conductivity of LSC (top) and LSF (bottom) at constant $\mathrm{pO}_{2}{ }^{2-4}$ 
LSC

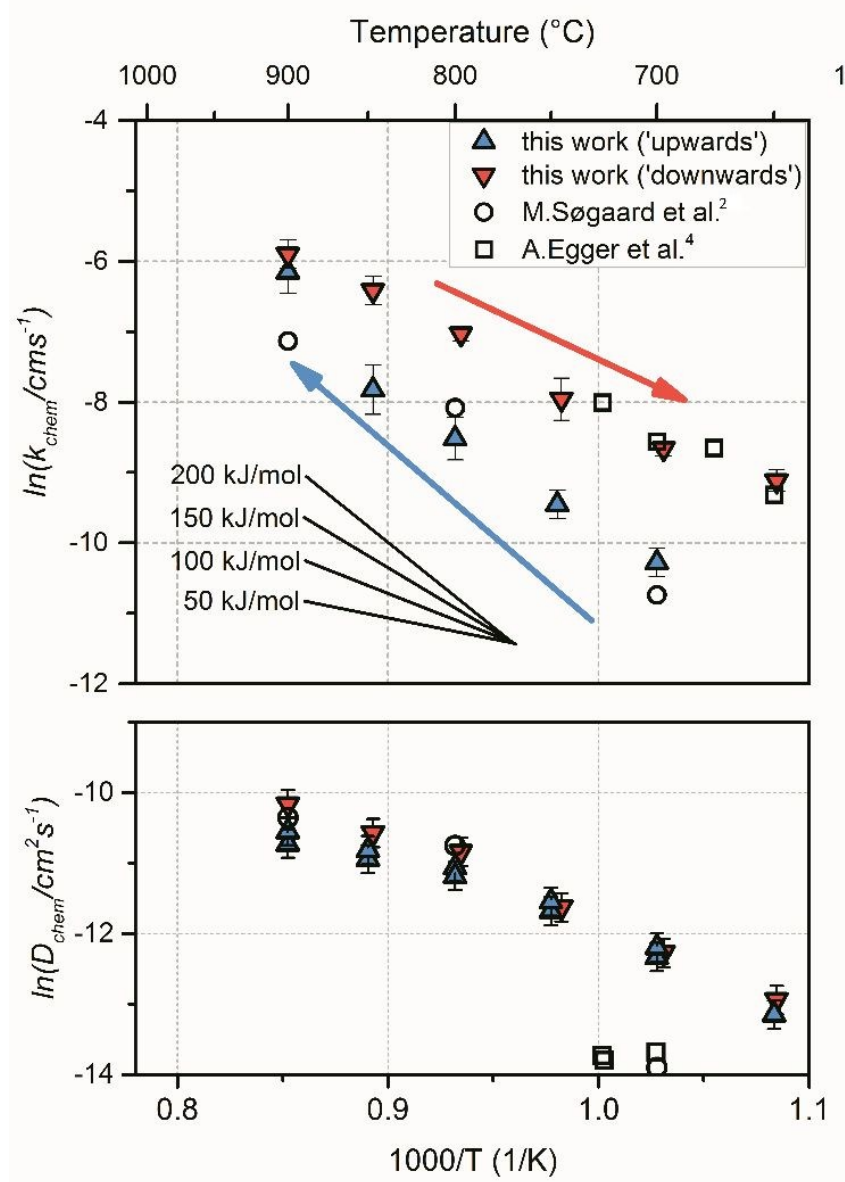

LSF
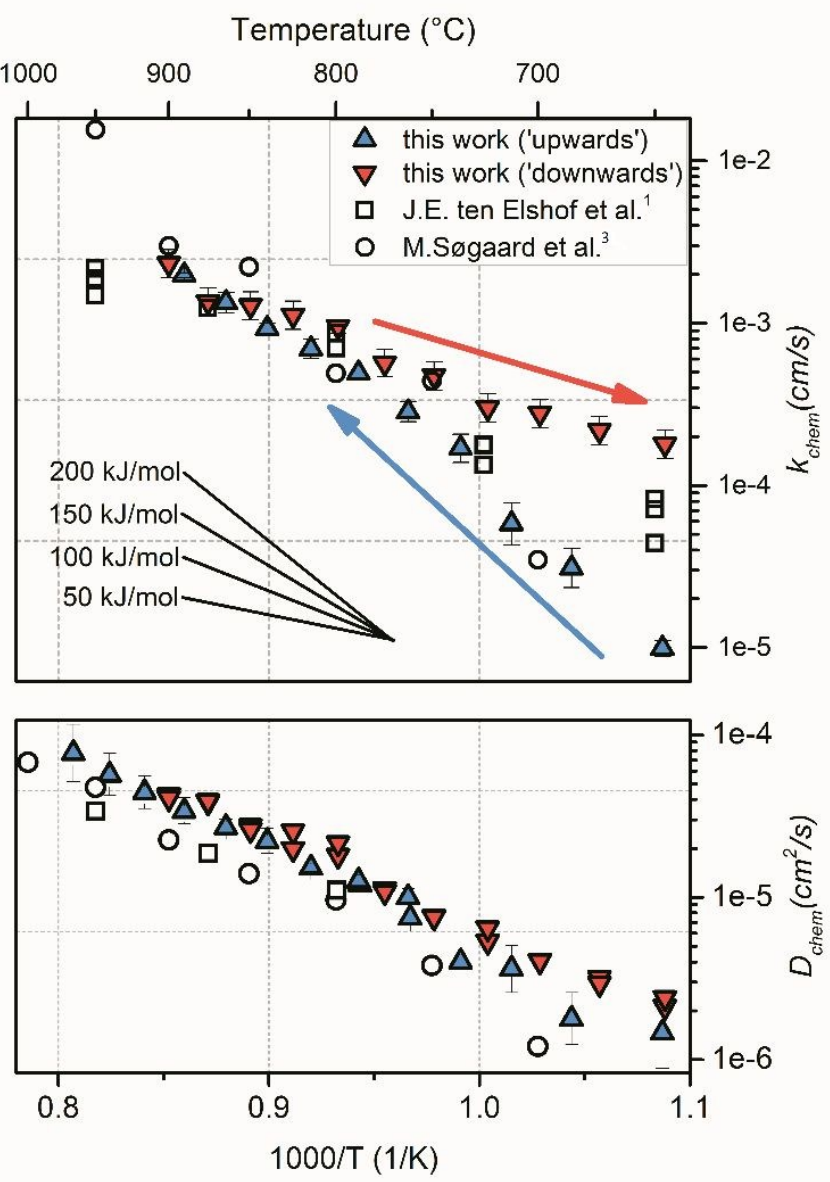

Fig. 2. Arrhenius plots of surface oxygen exchange ( $k_{\text {chem }}$ ) and chemical diffusion coefficient ( $D_{\text {chem }}$ ) of LSF (left) and LSC (right) at pO $\mathrm{O}_{2}=0.1$ bar. ${ }^{1-4}$ "Upwards" and "downwards" refer to measurements from low to high temperatures and vice-versa, respectively. 
a)

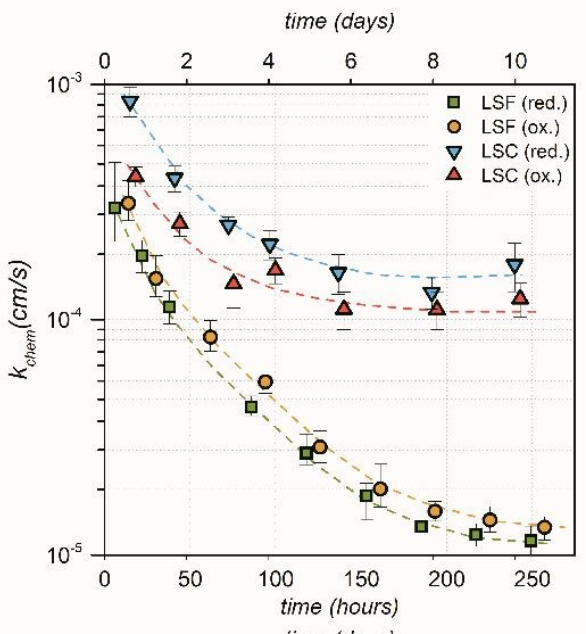

View Article Online DOI: 10.1039/C9TA02607J

b)

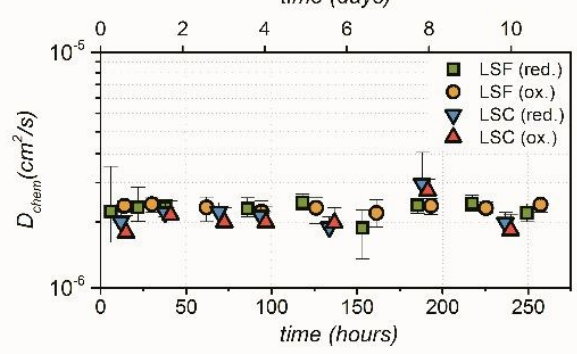

time(days)

c)

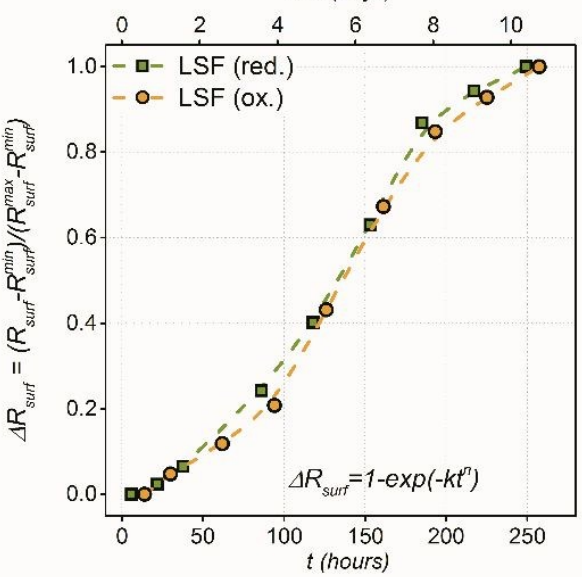

d)

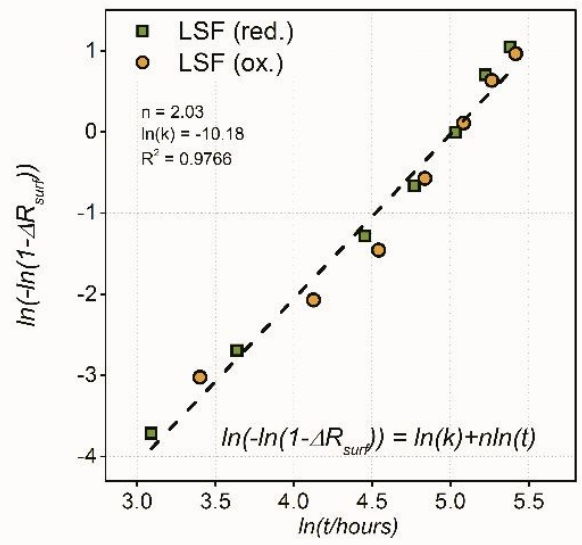

Fig. 3. Long term stability of a) $k_{\text {chem }}$ and b) $D_{\text {chem }}$; c) Normalized surface resistance as a function of time follows S-shaped curve - a characteristic of phase transformation process; d) Linearization of S-shaped curve allows determination of Avrami constants $n$ and $k$. Time scale shown on the $x$ axis represents the time that had passed since the end of the thermal treatment at $1000^{\circ} \mathrm{C}$. All measurements were performed at $650^{\circ} \mathrm{C}$ and $\mathrm{pO}_{2}=0.1$ bar (end pressure). 


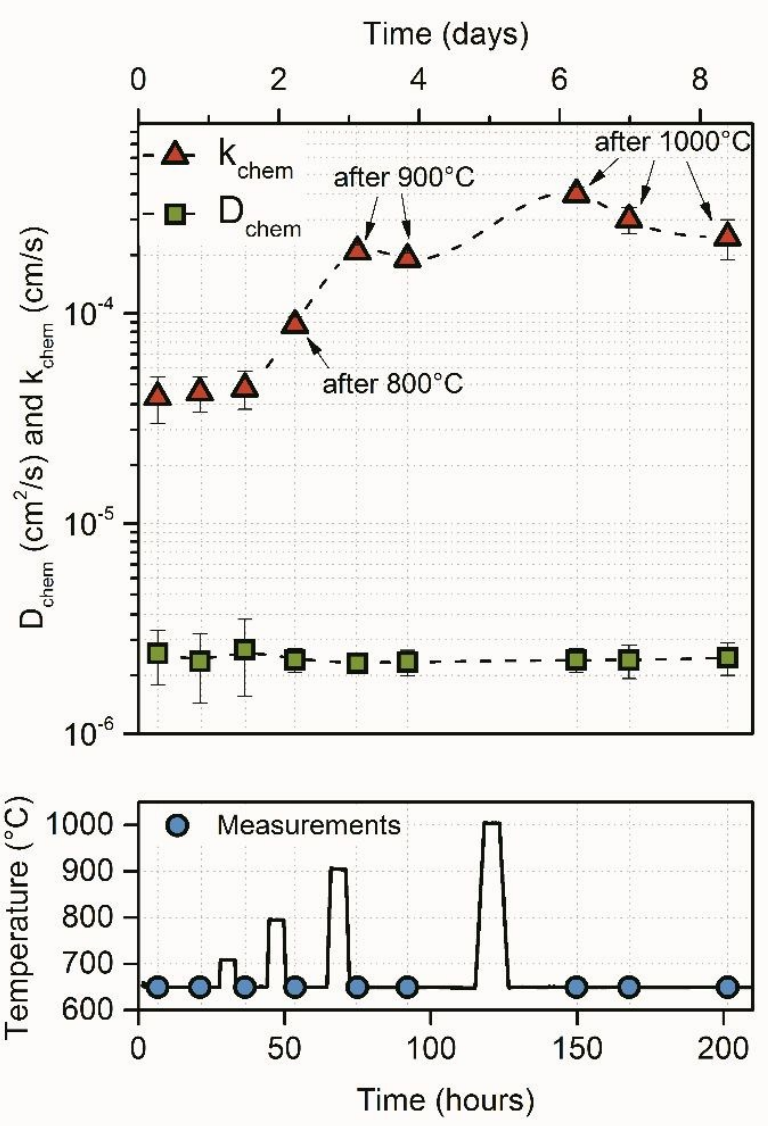

Fig. 4. The effect of thermal treatment at different temperatures on surface oxygen exchange of $\mathrm{LSF}$ measured at $650^{\circ} \mathrm{C}$ and $\mathrm{pO}_{2}=0.2$ bar (end pressure) 


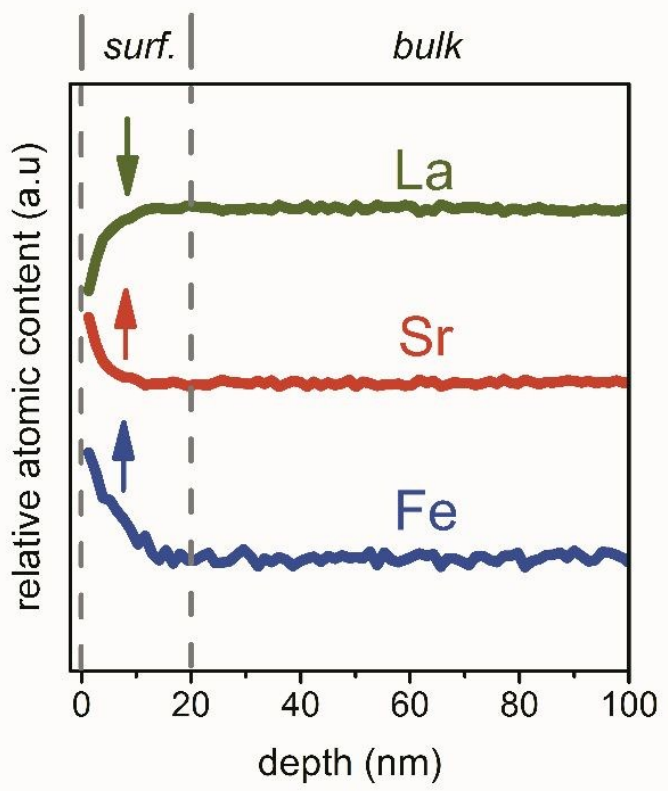

Fig. 5. ToF-SIMS profiles of the surface of LSF sample after ECR experiments 


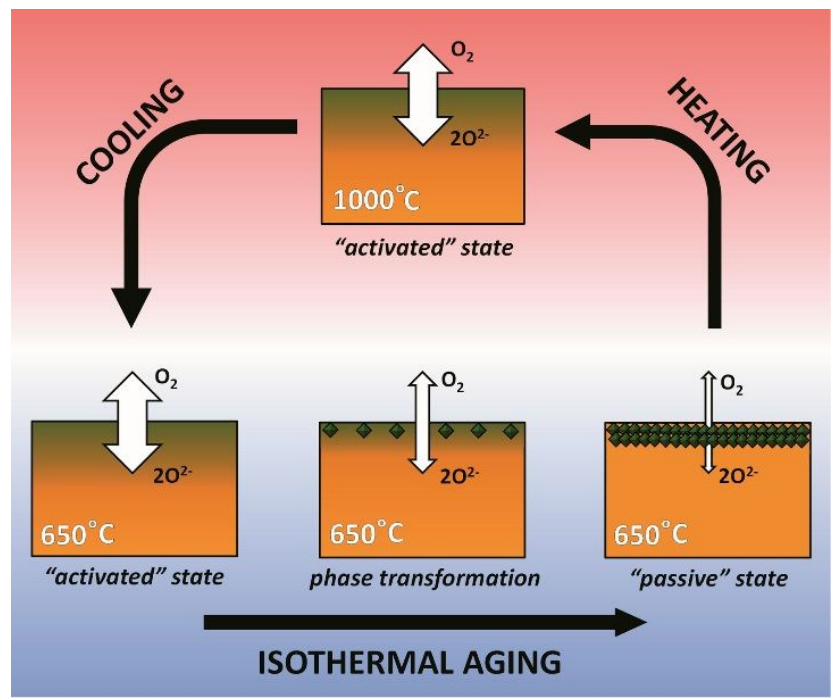

Fig. 6. An illustration of the activation mechanism and possible connection with surface reconstruction. Green shades stand for increased amounts of strontium related to bulk (yellow shades). This region is estimated to be approximately $20 \mathrm{~nm}$ thick (see Figure 5). The hypothesis is that strontium enriched surface layers of perovskite or perovskite-like structure (e.g. Ruddlesden-Popper) are being transformed to less active (passive) secondary phases (green diamonds) after aging at $650^{\circ} \mathrm{C}$. High-temperature thermal treatment leads to dissolution of secondary phases in perovskite lattice and the whole process is reversible. 


\section{Joyurnal of Material's Chefragistrybat 16 \\ $1000^{\circ} \mathrm{C}$ \\ "activated" state

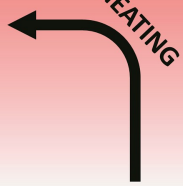

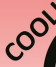

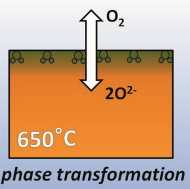

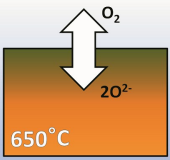

"activated" state

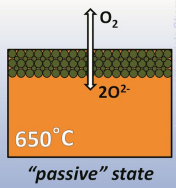

"passive" state 